\title{
Staff and patient feedback in mental health services for older people
}

Herefordshire Community Health (NHS) Trust, Stonebow Unit, County Hospital, Hereford, UK

Dawn J R Brooker, consultant clinical psychologist

School of Psychology, University of Birmingham Dawn J R Brooker, honorary lecturer

Worcestershire Community Health Care (NHS) Trust

Carole J Dinshaw, advanced nurse practitioner

Correspondence to: Dr Dawn J R Brooker, Clinical Psychology Services for Older People, Herefordshire Community Health (NHS) Trust, Stonebow Unit, County Hospital, Hereford, England. HR1 2ER. Tel: 01432 355444 ext 5579; fax: 01432 364058.

Accepted for publication 2 March 1998

\author{
Dawn J R Brooker, Carole J Dinshaw
}

\begin{abstract}
Objectives-To compare the views of patients and staff on the quality of care provided on a psychogeriatric assessment ward over a five year period. To describe the quality improvements which were made as a result of their respective comments.

Design-Structured interviews were conducted with both patients and staff to obtain qualitative feedback and suggestions for improvement. An analysis of the percentage of positive and negative comments made by both patients and staff was used to compare the levels of satisfaction on a variety of aspects of the service provided.
\end{abstract}

Setting-Psychogeriatric inpatient assessment ward.

Subjects -75 patients and 85 staff interviews were conducted.

Main measures-Structured interviews covering various aspects of service quality.

Results-Staff and patients picked up on different aspects of service quality as important. Quality improvements which arose from the interviews were clearly different. Generally patients were more positive about the physical environment and standards of professional care than staff, but less positive about issues of privacy, social interaction, and empowerment.

Conclusions-The perspectives of patients and staff in this area are not interchangeable. Both series of interviews led to several positive changes in the quality of care. Interviews with staff seem to have been valuable in a low morale situation. A structured interview format provided patients with an opportunity to feedback openly and led to changes in service quality which would not otherwise have occurred.

(Quality in Health Care 1998;7:70-76)

Keywords: questionnaire; patients, staff; mental health; elderly; satisfaction

\section{Introduction}

Collecting the views of those who use services and those that provide them is common practice in quality assurance. In Donabedian terms, users of health services are often able to provide useful insights into the process and outcomes of that service. Staff who are directly involved in service delivery often have useful insights into the structural aspects of how care is organised and prioritised. Seeking out the views of staff can also help them feel empow- ered to bring about positive change in services they provide. In a specialty such as old age psychiatry, staff often feel as disempowered as the patients they serve, and, as such, think that they are powerless to bring about quality improvements. The fact that their views are being sought gives a powerful message to them that they hold many of the keys to quality improvements within their own hands.

Collecting the views of users of health services dates back to the 1960 s. Several studies have been reviewed that paved the way for much of the work on user feedback since that time. ${ }^{1}$ This includes the work of Winifred Raphael who conducted many unstructured interviews with patients, staff, and committee members in four general hospitals. She then developed a questionnaire for patients, staff, and visitors to hospitals. Its influence on subsequent surveying of health consumers in the United Kingdom has been enormous.

After the creation of the Community Health Councils in 1974 most satisfaction surveys were instigated by this body. Most have never been published. The degree of involvement and commitment of local National Health Service (NHS) management would usually be the deciding factor in whether or not recommendations were acted on.

After the NHS Act 1990 providers had to supply purchasers with details of the range, the activity levels, the cost, and the quality of services that they could provide. In many cases this included supplying purchasers with details of feedback on satisfaction from service users. Feedback on levels of patient satisfaction with services thus took on a new dimension.

Problems in collecting meaningful user feedback on health services have been highlighted by several writers. ${ }^{1-3}$ Published research in this area rarely indicates what the impact of collecting feedback has been on the quality of services provided. ${ }^{4}$ Issues which require special consideration when trying to gain meaningful feedback from elderly service users include ${ }^{5}$ :

- The greater degree of physical and sensory disabilities in this age group making it more difficult for elderly people to participate

- The very high level of dependency which elderly people have on health care means they are often more fearful of being critical in case services are withdrawn

- The deficits in intellectual function caused by dementias and stroke disease means that a considerable proportion are unable to supply verbal or written feedback

- The general attitude of deference to authority figures which prevail in the current 
cohorts of elderly people means they are less likely to be critical

- The institutional agism which exists in many services increases the likelihood that the views of elderly service users will not be gathered or listened to.

It was suggested that structured or semistructured interviews, which take place away from the clinical setting and which are conducted by a skilled interviewer who as not been directly involved in the care of elderly people, can go some way to countering the effects of these obstacles. ${ }^{5}$

Professional staff can also offer useful feedback on their patients' needs. There is some evidence to suggest that nurses can usually identify sources of distress for the "average" patient in their care. There was a general accuracy in describing the sorts of concerns groups of patients were likely to experience but little agreement over particular worries of individual patients. ${ }^{6}$

A study of elderly patients and nursing staff highlighted similar problems of the ability of nursing staff to accurately determine sources of distress for their individual patients. ${ }^{7}$ As in the other study, ${ }^{6}$ however, nurses showed that they could accurately perceive the sources of distress that would concern the average patient. Comparison of the ability of general and psychiatric nurses to accurately identify the needs of their patients showed very little difference between the two groups in their ability to identify the needs of individual patients. ${ }^{8}$ When describing the needs of the average patient however, the psychiatric nurses' views were much more accurate.

On the basis of this it would seem that reliable data can be provided by staff commenting on issues of service quality which might affect their patients generally. This is particularly important in the care of elderly people when the views of patients may not be as easily accessible as those from younger patient groups. With this patient group, the staff's role as patients' advocates often becomes of prime importance.

THE PRESENT STUDY

In the late 1980 s we were working on a psychogeriatric assessment ward as a clinical psychologist and ward sister respectively. Standards of care were poor and staff morale was low. In an effort to change this situation it was decided to conduct a series of confidential interviews with staff to gather their suggestions on how things could be improved. After these interviews, the results were fed back to the whole team including the consultant and the operational manager responsible for that ward. Many of the suggestions made by the staff group were put into action. One of the suggestions was that we should carry out similar interviews with patients when they were discharged from the ward. Over the next four years patients were interviewed on discharge. The practice of interviewing staff about service quality also continued on an annual basis for this four year period. The aims of this paper are to examine the differing perspectives of staff and patients on the ward over this period and to consider the action that was taken as a result of their feedback.

\section{Method}

SETTING AND STAFF

The 24 bedded assessment ward was based in a small psychiatric unit of four wards which served the local city catchment area. The ward catered for patients over 65 with both organic diagnoses (dementias) and for the full range of functional mental health problems. Average duration of stay was about six weeks although there was enormous variation within this. The ward was mixed sex with separate washing and sleeping facilities. The ward was served by a single consultant team. Staffing ratios were consistent with the national picture in the United Kingdom at the time. Nursing staff were generally four per shift supported by a ward manager and housekeeper. Input from occupational therapy, physiotherapy, and clinical psychology were patchy at times but improved over the period of this study. The interviews with staff and patients had the full support of the operational manager and the consultant in old age psychiatry. Levels of patient engagement were also recorded as an audit of care throughout this period. ${ }^{9}$

\section{TOOLS AND PROCEDURES}

\section{Staff interviews}

Structured interviews were based on questionnaires originally devised by Raphael and Mandeville ${ }^{10}$ in the King's Fund survey into the lives of elderly people in hospital. The interviews had a set format and the interviewer recorded answers verbatim. The interviewers could help staff to clarify and develop their ideas if necessary but did not contribute ideas of their own. Staff were asked to comment on what they thought was good about the following aspects of care and what they thought could be done to make things better.

- Meals-timing, nutrition, suitability

- Physical environment-bedrooms, day rooms, bathrooms, toilets, and visitors' rooms

- Furniture-chairs, beds, soft furnishing

- Activities on the ward-timings, appropriateness, quality, and quantity

- Patient choice-degree of patient autonomy and empowerment

- Privacy-physical aspects, degree of respect and dignity, confidentiality

- Social interaction-between patients and how this was facilitated

- Care provided-general standards of nursing, medical, and other care

- Staff training-level and appropriateness

- Consultation with staff-relations between staff and wider hospital management

- Staff relationships-between different grades, shifts, and disciplines.

Comments were based on the 12 month period before the interviews.

Interviews with staff were conducted over a three week period in each year during the five years reported here. In the first year DJRB 
Table 1 Positive comments made at interviews by staff and patients (\%) on various aspects of service quality (years 1 to 5)

\begin{tabular}{|c|c|c|c|c|c|c|c|c|c|c|}
\hline \multirow[b]{2}{*}{ Topic } & \multicolumn{2}{|l|}{ Year 1} & \multicolumn{2}{|l|}{ Year 2} & \multicolumn{2}{|l|}{ Year 3} & \multicolumn{2}{|l|}{ Year 4} & \multicolumn{2}{|l|}{ Year 5} \\
\hline & $\begin{array}{l}\text { Staff } \\
n=13\end{array}$ & $\begin{array}{l}\text { Patients } \\
n=0\end{array}$ & $\begin{array}{l}\text { Staff } \\
n=15\end{array}$ & $\begin{array}{l}\text { Patients } \\
n=17\end{array}$ & $\begin{array}{l}\text { Staff } \\
n=19\end{array}$ & $\begin{array}{l}\text { Patients } \\
n=20\end{array}$ & $\begin{array}{l}\text { Staff } \\
n=18\end{array}$ & $\begin{array}{l}\text { Patients } \\
n=22\end{array}$ & $\begin{array}{l}\text { Staff } \\
n=20\end{array}$ & $\begin{array}{l}\text { Patients } \\
n=16\end{array}$ \\
\hline Meals & 28 & & 75 & 75 & 88 & 80 & 79 & 90 & 86 & 78 \\
\hline Physical comfort & 11 & & 61 & 60 & 65 & 82 & 69 & 90 & 49 & 93 \\
\hline Activities & 0 & & 57 & 58 & 100 & 61 & 83 & 80 & 50 & 48 \\
\hline Social interaction & 50 & & 94 & 60 & 100 & 58 & 95 & 65 & 100 & 55 \\
\hline Patient empowerment & 20 & & 72 & 69 & 100 & 65 & 67 & 58 & 67 & 55 \\
\hline Privacy & 50 & & 82 & 40 & 95 & 56 & 92 & 70 & 87 & 68 \\
\hline Nursing care & 63 & & 57 & & 100 & & 92 & & 95 & \\
\hline Medical care & 63 & & 63 & & 72 & & 65 & & 61 & \\
\hline Others care & 36 & & 62 & & 77 & & 61 & & 40 & \\
\hline Care and treatment: & & & & 90 & & 100 & & 95 & & 90 \\
\hline Staff training & 0 & & 87 & & 50 & & 24 & & 44 & \\
\hline Staff consultation & 33 & & 100 & & 100 & & 77 & & 94 & \\
\hline Staff relations & 37 & & 53 & & 100 & & 81 & & 92 & \\
\hline
\end{tabular}

conducted all of the staff interviews. In subsequent years the staff interviews were usually carried out by assistant psychologists working in other parts of the service. The interviews were clearly structured and seemed to be reliable in the information obtained by the different interviewers.

An attempt was made to interview all staff who worked on the ward including night staff and members of the multidisciplinary team. Interviews usually took place in an interview room on the ward. Although staff were encouraged to participate, they were always aware that the interviews were voluntary. The confidential nature of the interviews was always emphasised. The interviews were collated into a report which summarised staffs' views and ideas for service improvements but did not link particular staff to particular comments.

\section{Patient interviews}

Interviews with patients started in the second year of the five years reported here. Interviews with patients on discharge from the ward were used as a means of monitoring service quality throughout the year. This had been suggested during the staff interviews in the first year of the cycle. Interviews were carried out on the day of discharge, when the patient would be interviewed in a private office on the ward. The interviewer was always a professional who had not been involved in that patient's care. Over the years about five different interviewers were used. These included psychologists and senior nursing staff who worked in a different part of the service. The interviews were clearly structured to maintain reliability between interviewers.

An effort was made to approach all patients on discharge. Once a discharge date had been agreed, the ward staff would contact the person designated to carry out the interviews. The main factor in selecting patients for interviews was whether the interviewer could arrange to see the patient before discharge. If an interview was possible, the interviewer made it clear to patients that the discharge interview was optional. Patients were assured that if they declined then this would not be held against them in any way. Patients were also given the assurance that they could stop the interview at any time. Again this option was rarely taken up.
They were also given the assurance that their anonymity would be maintained but that all their comments would be taken seriously.

Patients who had dementia were not interviewed. Because of severe problems with verbal recall of recent events, these patients cannot reliably use an interview format to express their satisfaction.

The patients' interviews were also based on those used in the King's Fund study ${ }^{10}$ along with some additional questions. The following topics were covered:

- Meals-timing, nutrition, suitability

- Physical environment-bedrooms, day rooms, bathrooms, toilets, and visitors' rooms

- Furniture-chairs, beds, soft furnishing

- Activities on the ward-what people most enjoyed, appropriateness, quality, and quantity

- Patient choice-degree of perceived autonomy and empowerment

- Privacy-physical aspects, degree of respect and dignity, confidentiality

- Social interaction-who patients spoke to most, how this was facilitated

- Care provided-standards of care and treatment including knowing the names of key staff.

The patients' interviews had a set format and the interviewer recorded answers verbatim. The interviewers could help patients to clarify their answers if necessary. As in the staff interviews, patients were asked to comment on what they thought was good about the different aspects of service quality and what could be done to improve them.

The interviews were summarised in an anonymous format and were fed back to the monthly management team meetings. Decisions were made at these meetings about action to be taken on the basis of the interviews with patients. This feedback was also presented at the annual "away-days" in years 2-5 of the cycles presented here.

\section{Content analysis of interviews}

The interviews consisted of open ended questions and provided a wealth of qualitative information. For the purposes of this paper a simple content analysis was carried out. All the comments were listed and were grouped in the following categories. 
Table 2 Summary of changes in quality initiated by comments of staff and patients

\begin{tabular}{ll}
\hline Changes initiated by staff & Changes initiated by patients \\
\hline Changes in timing of meals to fit into patients day & $\begin{array}{l}\text { Salt and pepper available on tables at meal times } \\
\text { Increased flexibility in preparing snacks on the ward } \\
\text { Introduction of mid-afternoon tea as a social occasion }\end{array}$ \\
Ward physically up graded & $\begin{array}{l}\text { Locks on basins replaced when missing } \\
\text { Missing keys to lockers fixed when broken }\end{array}$ \\
Ward pets (cats, fish, and budgie) & Separation of sleeping areas for those with dementia where possible \\
Clarification of staff roles and regular paramedic input & Less formal decor in visitors room \\
Staff training geared towards elderly care & Exercises to music given priority by physiotherapy \\
Time of staff sensitivity sessions changed to make them accessible to more staff & Staff name badges \\
Furniture and wheelchairs refurbished & Raised staff awareness of lack of patient empowerment \\
Purchase of tablecloths and mats & Separate assessment wards for dementia and functional mental health problem \\
Purchase of non-institutionalised crockery & in new hospital \\
Donations of ornaments, pictures, and plants in the ward & \\
Creation of visitors' room for greater privacy &
\end{tabular}

(1) Positive comments about the area under discussion - that is, things that were already happening in the ward which were satisfactory to staff or patients.

(2) Negative comments about the area under discussion which suggested dissatisfaction.

These categories for the content analysis were defined by DJRB. The comments were then assigned to the different categories by the author and a "blind" independent assessor. Concordance rates of between $87 \%$ and $100 \%$ were achieved with this method. The positive and negative comments were expressed as a percentage of the total number of comments for each individual topic area.

\section{Feedback to staff and managers}

The reports were circulated to all staff working on the ward and were fully discussed at a ward away-day held annually in the month after the staff interviews. All the ward team were invited to attend the away-day. These included nursing, medical, and ancillary staff, professions allied to medicine, and the operational manager responsible for the ward. The ward was covered by other hospital staff to enable this to happen. At the away-day the staff and patient feedback would be presented formally, as would be the results of the patient engagement evaluation. The team would then split into small multidisciplinary groups to discuss what quality improvements could be made. An action plan for quality improvements for the year after was drawn up at the end of the day. This was monitored during ward management meetings throughout the year.

\section{Results}

STAFF INTERVIEWS

Eighty five staff interviews were conducted (96\% were with nursing staff) over the five year period. Table 1 shows the numbers completed in each year. Interviews from other disciplines usually accounted for two to three each year. An attempt was made to interview all staff. Sickness, annual leave, and other practical issues limited the number that could be done. Percentage of day staff interviewed varied from $78 \%$ to $93 \%$ over the years. It was not possible to interview night staff during the first year but in subsequent years $100 \%$ were interviewed.

From table 1 it can be seen that there was a dramatic increase in the number of positive comments made by staff on every single aspect of the structured interview between years 1 and
2. The only exception to this was number of positive comments about nursing and medical care.

Changes in staff

During the first year of the cycles reported here about $40 \%$ of the trained nursing staff moved post. One of the key criteria in selecting new staff was a commitment to working with elderly people in a positive manner. The staff group remained stable over the next four years.

\section{PATIENT INTERVIEWS}

Seventy five patients were interviewed over four years. This equates to about $40 \%$ of patients with a functional mental health problem who were discharged from the ward during this period. Thus, a sample of about $50 \%$ of discharged patients were interviewed which amounted to an average of two interviews a month. Of the patients asked, 95\% agreed to be interviewed. Table 1 shows the actual numbers.

For the purpose of the analysis the interviews were grouped together in the 12-month time bands. They were compared with staff interviews relating to the same time frame. Table 1 shows actual numbers completed in each time frame.

\section{QUALITY IMPROVEMENTS}

Many of the suggestions that staff had made during the first year's interviews were put into practice during the next 12 months. Table 2 shows these, along with the changes in later years that were made as a result of suggestions of staff and patient. The first eight changes as a result of staff feedback were made between years 1 and 2. Other changes were often made as a result of the interviews but the ones listed in table 2 are the changes that were sustained.

\section{Meals}

Several changes were made in this area as a result of comments made (table 2). Staff comments tended to focus on nutritional issues rather than food for pleasure. Staff often asked for more fresh fruit whereas patients consistently rated the puddings and cakes as their favourites. Staff were also keen for service users to be able to enjoy traditional English meals that they thought would be culturally suitable to the patient group whereas several patients commented that they had enjoyed the curries and spicy dishes that had been offered. Many 
positive comments from patients were made about the opportunity to make a cup of tea whenever they wanted. Some negative comments from staff regarded this as a safety hazard.

\section{Physical environment}

Patients usually commented on the social dimension of the environment rather than the purely physical. For example, when patients were asked about the day room, they were much more likely to say: "Its friendly and easy going" rather than to comment on the state of the carpet. Patients often commented positively on the ward pets, which were rarely mentioned by staff (except a few complaints by staff about the welfare of the pets). Staff and patients selected aspects of the environment which were most meaningful to them. For example, patients would usually comment on the comfort of the beds or chairs whereas staff would more often comment on ease of cleaning or making.

Staff generally had different expectations of the physical environment than patients. Table 1 shows that as staff make fewer positive comments about the physical environment, patients make more. The hospital was due for relocation after year 5 and was looking decidedly dilapidated to the eyes of the staff. Patients, however, made more and more comments about the cleanliness of the ward from year 3 onwards. This coincided with the ward having permanent domestic staff.

Table 2 shows the changes made as a result of comments. From year 3 there was a weekly audit of plugs, keys, and toilet locks, which dramatically decreased the number of problems in this area. These items were only rarely mentioned by staff in their interviews as a cause for concern.

Privacy

Staff generally made many more positive comments about the degree of privacy afforded to patients than patients did themselves. Curtaining around bed and washing areas was the main physical means of privacy. Most of the positive comments by patients were to do with the appropriate use of this. Most of the negative comments were to do with the structural layout of the ward rather than insensitive practices by staff. This was never picked up by any of the staff interviews as an infringement of patient privacy.

Negative comments from patients often focused on having to share bedroom areas with those who were very disturbed. This led to a ward policy not to mix those with dementias and functional mental health problems in the same bed areas wherever possible from year 2 onwards. When the ward was relocated after year 5 and a second assessment ward was opened it was decided to operate completely separate assessment facilities for the two patient groups. This decision was based to a large extent on the negative comments that had been collected in the previous four years.

A visitors' room was made available on the ward from year 3 onwards where patients could see their visitors in comparative privacy. Staff viewed this very positively. However, only $41 \%$ of patients said they actually used it to see their visitors. Others preferred to see their visitors off the ward or in their bedroom area saying that it was too official to see visitors in there. The room was also used as a small meeting room for patient reviews and staff meetings, and although steps were taken to make it a less formal room by the addition of pictures etc, the comments about "officialdom" continued.

\section{Activities for patients}

Patients' replies focused on activities that they had found particularly enjoyable. Staff focused on their perceived therapeutic benefits. Contrary to the stereotype of the types of activities that elderly people enjoy, the most popular was "exercises to music". This was led by a physiotherapist. The positive feedback ensured that this activity remained a priority. Bingo was the seventh most popular, being less popular than reminiscence groups, singalongs, and quizzes.

There was a fall off in positive comments from staff and patients in year 5. This coincided with a decrease in occupational therapy and clinical psychology input to the ward with a decreased level of organised activities.

\section{Social interaction}

Social interaction was viewed much more positively by staff than by patients. Staff saw themselves as actively encouraging interactions. Patients viewed social interactions as difficult primarily because they were sharing their environment with others displaying "peculiar" behaviours. Also, most of those interviewed were in hospital because they were clinically depressed and wanted to withdraw from social contact.

Most patients (42\%) named another patient as the person they had spoken to most often. This was usually someone who was admitted at the same time or with whom they shared a bedroom area. Thirty per cent said they had spoken most often to nursing staff, and $2 \%$ to medical staff. Eight per cent of those interviewed claimed to have spoken to no-one.

\section{Patient empowerment}

This was another area where, generally, staff made more positive comments than patients. Negative comments from patients tended to reflect subtle pressures to conform, or reflected their low expectations of their rights to have a say in their treatment. The following quotes from the interviews help to illustrate these points.

"At bed time they don't actually tell you to go to bed but they like to clear you all out"

"At tablet time you don't get a cup of tea until you've taken your tablets"

"I'd say that I had enough say considering my age"

"I could get up and use the toilet whenever I wanted" 
"I sat on a bench outside today (last day in the hospital) but before then I never knew that I was allowed to go out".

Staff were generally very upset when this sort of information was fed back to them and their decrease in confidence to empower their patients is reflected in their negative comments in years 4 and 5. The large degree of "permission giving" that this particular patient group requires to take up their basic rights cannot be underestimated.

Nursing care, medical care, and other care Staff were positive about the quality of professional care that patients received from year 3 onwards. Patients almost without exception rated their general care and treatment very positively. They found it very difficult to differentiate between nursing and other professional staff.

Patients' responses to questions on whether or not they could identify their primary nurse and doctor was always poorer than staff expected it to be. Twenty seven per cent named a nursing assistant as their primary nurse and a further $21 \%$ named the ward manager. The introduction of name badges in year 4 improved the situation slightly but not significantly. The nurses on the ward often did not equate to the elderly persons expectation of what a nurse should do. Comments such as: "they're not nurses, they're like organisers" were not uncommon. This may have been exacerbated as no staff wore uniform.

Fifty four per cent of patients could name a doctor although a further $26 \%$ could describe one! Patients rarely differentiated between consultant staff and more junior staff.

\section{Staff training}

There was an enormous improvement in staff satisfaction with training from year 1 to 2 which probably reflected the large amount of training staff received in that year. However, after this period dissatisfaction with training grew.

Consultation with staff and staff relationships

These improved over the years and remained stable. The interviews themselves were an excellent vehicle for helping staff to realise that they had been consulted and many of the positive staff comments bore witness to this.

\section{Discussion}

The interviews seemed to be sensitive to changes in practice. Their most useful function from an organisational perspective is that they produced a wealth of ideas for service improvements, many of which were revenue neutral. Other initiatives did have a financial cost but the interviews were a useful means of trying to prioritise funding. Even in year 1, when the ward morale was very low, lots of positive suggestions were made. From each set of interviews some of the suggestions for improvement were actioned thus increasing staff motivation and ownership of quality improvements.

Taken as a whole staff were generally less positive about the physical environment and standards of professional care than patients. Patients were generally less positive about the degree of privacy, social interaction, and sense of empowerment that they thought they had. Changes in practice were initiated from both staff and patient feedback. Patients often commented on quality shortfalls which staff did not pick up on at all and often held opinions which challenged stereotypes. Examples of this were the positive comments about highly spiced dishes on the menu and requests for more exercise classes from patients whereas staff were requesting more traditional English fare and nightly bingo on their behalf.

The different perceptions on the various aspects of service quality highlight the dangers of taking staff opinion as a proxy for the patient's voice. These data suggest that if there is a choice between collecting patients' views or staff views then patient feedback is a better investment. We cannot assume that the views of patients and staff are interchangeable. Both sets of interviews led to quality improvements in structure and process.

Patients seemed to be fairly open in their feedback. This particular client group, for the reasons set out in the introduction, are often difficult to gain feedback from. This specific group, who were often recovering from a major depressive episode, would probably be less motivated than most to make an effort to respond. The way in which the interviews were organised seemed to facilitate their cooperation in that the effort was made by the service providers and not by the elderly people themselves. The richness of the feedback provided here could not have been gained through written feedback. Discussion groups of discharged patients would have been very difficult to organise. Satisfaction checklists certainly would not have picked up some of the subtler feelings - such as those to do with privacy or empowerment.

Staff also seemed to be open in their comments during the interviews. The emphasis based on confidentiality was important to many staff. No names were written on the interview schedules and staff had the opportunity to read what the interviewer had written. Staff consistently made more comments on meals and the physical ward environment than they did on potentially more sensitive areas such as staff relationships and consultation. This would suggest they were more open about some areas than others.

Collecting feedback in this way, however, is time consuming. Interviews with patients took about half an hour. After this, interviews had to be summarised so that they could be fed back in an anonymous format. Interviews with staff could take from 20 minutes to an hour with the average being about half an hour. In year 1 all of the staff interviews took over an hour to complete as many staff used them to give vent to their feelings of frustration with poor practice. Thus, the investment of time in a low morale service is higher. Carrying out the interviews, collating them, and summarising them took an individual member of staff about two weeks of full time work each year. In some 
respects, the investment in staff interviews had diminishing returns in that most changes took place between years 1 and 2 .

In year 3 staff were given the option of either meeting as a group to discuss improvements to practice or of having individual interviews. Most voted for interviews. In year 4 staff were given the option of completing a questionnaire instead of having an interview. Only three staff opted for the questionnaire. The quality of the written responses, however, was not helpful. There was a strong tendency to make global criticisms rather than constructive ones.

It seems from this that staff valued the opportunity to have interviews on service quality. A further advantage of the interview format is that if the interviewer is skilled, they can be very useful to help staff clarify and develop their ideas on service quality. The publications reviewed earlier on the ability of nurses to identify general rather than specific concerns is of interest here. It is our experience of interviewing staff that they often have a great deal of knowledge about good quality care. They often are not good, however, at articulating what they know. The interview was an opportunity for staff to find their voice on issues of quality.

Likewise, in the interviews with patients, a skilled interviewer may pick up dissatisfactions that are quite straightforward to remedy once they are known about. Without the interview opportunity many things would not have come to light which might otherwise have gone on to cause further distress or to have become complaints.

Another very powerful effect that the patient interviews had were on staff morale. The overall tone of patient feedback was positive, and although there are all sorts of reasons other than a good quality service as to why that might be, it is rewarding for staff to get this sort of feedback. This is particularly important in psychogeriatric care where positive feedback may be less available than in other areas. We have had similar experiences in interviewing relatives of those patients with dementia. Particularly in respite and day care the effects of carer feedback can be positive on staff morale. We have also used the structured interview process to evaluate the perceptions of patients receiving community based services which seem to have had a positive effect on morale and also led to quality improvements.

There were advantages to continuing the quality assurance cycles over such a long period. Staff trusted the process and knew that action would be taken as a result of it. It was not seen as a paper exercise. On the down side there was a tendency in later years with some ideas for improvement to be discarded as unworkable because they had been tried previously and had not been sustained. It could have been that they would have worked in later years because the setting conditions and skills of those involved had changed. Repeating cycles makes those involved very comfortable with the process and perhaps less likely to challenge practice.

The cycles in the format described here only came to a halt because of a merger between two health authorities. After the merger, the interviews with patients and carers were recommenced. A decision was made, mainly because of time constraints, to only interview ward managers, consultants, and heads of professional services rather than all those involved in service provision. On reflection, we have probably lost some of the richness that comes from seeking the views of staff at all levels of service provision. Also we may have lost some of the ownership of changes that have been made. We introduced Dementia Care Mapping as a means of evaluating the quality of direct care in formal dementia care settings with positive effect. ${ }^{11}$

On balance, although the interviews described in this paper were time consuming, the wealth of information provided, the sense of ownership engendered for staff, and the opportunity provided for clarifying ideas has made this a worthwhile exercise. Our experience suggests that staff interviews of the nature described here can be very useful in low morale situations. In the context of other services in which morale is satisfactory they may not be worth the investment of time. The list of quality improvements which were linked to staff feedback could have arisen without the interviews taking place. This would probably not be the case with the action arising from the patient feedback. With this particular patient group it is difficult to imagine another way in which the quality of feedback on patient experience could have been gathered which would not have involved an even greater investment of time.

We specially thank, as always, all patients and staff who participated, particularly Hilary Nissenbaum and Paul Pyke.

1 Jones L, Leneman L, MacLean U, Consumer feedback for the NHS: a literature review. London: King Edwards Hospital Fund for London, 1987

2 LeBow JL. Client satisfaction with mental health treatment; methodological considerations in assessment. Evaluation Review 1983;7:729-52.

3 Carr-Hill RA. The measurement of patient satisfaction. $\mathcal{F}$ Public Health Med 1992:14:236-249.

4 Ellis R, Whittington D. Quality assurance in health care. London: Edward Arnold, 1993

5 Brooker DJR. Issues in user feedback on health services for elderly people. British fournal of Nursing 1997;6:159-62.

6 Johnston M. Recognition of patients' worries by nurses and other patients. Br f Clin Psychol 1982:21:255-61.

7 Davies ADM, Peters MP. Stresses of hospitalization in the elderly: nurses and patients perceptions. $\mathcal{F}$ Adv Nurs 1983; 8:99-105

8 Farrell G A. How accurately do nurses perceive patients needs? A comparison of general and psychiatric settings. $\mathcal{F}$ Adv Nurs 1991:16:1062-70.

9 Brooker DJR. Quality assurance lessons learnt about putting it into practice. Psychologists Special Interest Group in the Elderly (PSIGE) Newsletter 1994;48:37-41.

10 Raphael W, Mandeville J. Old people in hospital: a survey of opinions of patients, visitors, and staff. London: King Edwards Hospital Fund for London, 1979.

11 Brooker DJR, Foster N, Banner A, et al. The efficacy of dementia care mapping as an audit tool: report of a threeyear British NHS evaluation. Ageing and Mental Health 1998;2:60-70. 